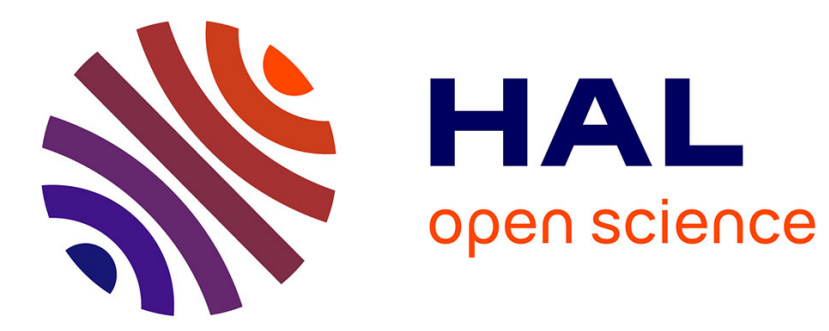

\title{
Dedicated system for structural health monitoring of aircraft Hardware system based on V-cycle model
}

Sabeha Fettouma Zedek, Christophe Escriba, Jean-Yves Fourniols

\section{To cite this version:}

Sabeha Fettouma Zedek, Christophe Escriba, Jean-Yves Fourniols. Dedicated system for structural health monitoring of aircraft Hardware system based on V-cycle model. The first IEEE International Symposium on Systems Engineering (ISSE 2015), Sep 2015, Rome, Italy. 5p. hal-01211475

\section{HAL Id: hal-01211475 \\ https://hal.science/hal-01211475}

Submitted on 5 Oct 2015

HAL is a multi-disciplinary open access archive for the deposit and dissemination of scientific research documents, whether they are published or not. The documents may come from teaching and research institutions in France or abroad, or from public or private research centers.
L'archive ouverte pluridisciplinaire HAL, est destinée au dépôt et à la diffusion de documents scientifiques de niveau recherche, publiés ou non, émanant des établissements d'enseignement et de recherche français ou étrangers, des laboratoires publics ou privés. 


\title{
Dedicated system for structural health monitoring of aircraft
}

\author{
Hardware system based on V-cycle model
}

\author{
Sabeha Zedek \\ LAAS-CNRS \\ 7 Avenue du Colonel Roche, 31031 \\ Toulouse, France \\ zedek@laas.fr
}

\author{
Christophe Escriba, Jean Yves Fourniols \\ LAAS-CNRS, INSA Toulouse \\ 7 Avenue du Colonel Roche, 31031 \\ Toulouse, France \\ escribe@1aas.fr , fourniols@1aas.fr
}

\begin{abstract}
Our main subject of interest is the Structural Health Monitoring in aeronautics. Most of our works are dedicated to the detection of delamination disbonds and cracks in heterogeneous (Composite) and homogenous (aluminum 2024) structures of an aircraft structure. To successfully combine detection and alert generation we based our approach on the use of new generation of chip called SoC (System on Chip). We tried to develop an autonomous system able to detect damages on aircraft structure. According to several previous results using FPGA (Field Programmable Analog Array), PSoC (Programmable System on Chip), we proved the principle of detection embedded to a programmable system, and we also saw the limits of this kind of system for a complex system combining conditioning and algorithms of detection. That's why we focused our effort on a more powerful chip called Zynq. The approach of development, test and implementation was based on an approach close to the $V$ cycle. The $V$ model represents a software development process that we adapted to the hardware conception. In this paper, we will describe our methodology and give some of the results we get during our experimentation about crack detection in aeronautic structures (Composite and Aluminum, we will also explain how development according to the $\mathrm{V}$ methodology helped us insure the good operation of the electronic system..
\end{abstract}

Keywords-Structural Health Monitoring; V-Cycle; Hardeware system; aeronautic.

\section{INTRODUCTION}

The process of implementing a damage identification strategy for aerospace, civil and mechanical engineering infrastructure is referred to as structural health monitoring (SHM) damage is defined as changes to the material and/or geometric properties of these systems, including changes to the boundary conditions and system connectivity, which adversely affect the system's performance [1]. One of the most important aspects of developing systems for structural health monitoring (SHM) is to insure the safety of structures and saving money. Nowadays materials in structures (aeronautics, civil engineering ...) are evolving, developing strategies for a better knowledge of their behavior and evolution over time is primordial. The chosen approach for to develop our system of detection was based on the V cycle model. Most of time used in software development, we based our co-design on it. The V- model represents a software development process, as it is applied to hardware development (most of time in co-design). $\mathrm{T}$ e advantages of $\mathrm{V}$ cycle lies in its inherently intuitive nature, easy reuse of model and portability across multiple platforms. Model-based control design is a time saving and cost-effective approach [2]. The $\mathrm{V}$ cycle is based on the principle of verification and validation, which enables the development of robust systems.

In this paper we will start by explaining the context of development, the methodology and finally we will expose the results.

\section{Structural HeAlth MONitoring SySTEM DESCRIPTION}

\section{A. Structural Health Monitoring for}

The SHM is a major challenge of our century. Aging airline fleets and the inherent changes to the rhythm of human life which changes considerably the stresses and thus the fatigue, forces us to develop a prevention strategies such as the establishment of SHM type of monitoring. The principle is not new, and relies heavily on NDT techniques (Nondestructive testing) has some differences pres. The SHM is a set of techniques much less cumbersome and does not necessitate disassembling structures [3]. Whatever the service structure, bridge, air, satellite ... and it is important to estimate its lifetime. On leaving the factory or at the end of a construction, we established a duration theoretical life. In order to expand our knowledge in terms of predictions, can follow the integrity and the evolution of the structure itself and prevent disasters in real time, the SHM can become an inexhaustible source of information for manufacturers. Thanks to an intelligent instrumentation, we could:

- Avoid too long workings of downtime (aircraft assets, closing roads and bridges ...) for inspection.

- Preventing disasters, at the detection point breaks or a high-failure risk.

- Provide key data to manufacturers for the improvement of products. 
- Change of maintenance procedures, reduce costs by avoiding mobilization Current fi qualified personnel when received are normal operation.

- Avoid heavy operations such as disassembling and reassembly. We focused in our work on system integration dedicated to the problematic of SHM. The project consisted on developing.

The first step of conception is a global view of how to start; we can see it on the figure 1. describing the several steps of conception. First of all, it's necessary to focus on the type of structure according to the type the weight and size, we can select several approaches or do our own one, we have to implement the approach test it and finally validated it

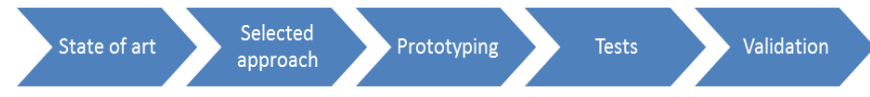

Fig. 1. General float of conception of the SHM system

\section{B. System description}

We focused in our work on system integration dedicated to the problematic of SHM. The project consisted on developing a generic platform that can meet the needs following the cycle presented in the following figure.

- Sensor choice for diagnosis: The dedicated sensors for detection of defects in structures are many. We have a large choice in this field, we saw most of them during our research works (the list wasn't exhaustive) [4]. Mainly the choice is determined by the type of material, the location of the sensor, the complexity of the room and area to be inspected, or of the interest of a system that can be interfaced to several sensor means.

- Embedded Intelligence systems are part of the progress smart environments (INTEGRATED actuators react to events and adapt to external conditions). This implies the development of adaptive algorithms able to apprehend a series of events. Concerning the SHM we could speak of events such as impacted on the structure, the system of energy levels or a change in the architecture of the network.

- Communication of the sensor nodes: here we have the choice between the wireless and the wired solution. According to the needs. Most of time we have to carry about serval parameters like:

- The sensor network

- The speed and reliability

- Installation and maintenance

- Durability (longevity of the system).

- Versatile architecture: one of our main objectives during the development was the developing of a smart system able of self-adaptability. It is necessary to have programmable devices that need to be configured in a way to adapt to external conditions. Whatever the entree, we need to discriminate and react accordingly; all automatically and autonomous way

- Multi-sensors strategy: A not insignificant aspect of the generic platform is the possibility to interface with multiple sensors. The main obstacle in this approach is the multitudes of possibilities. The sensors are not always compatible in: frequency voltage or current.

- Energy management: The energy needs are central to the development of all electronic devices. to manage a power supply with a strategy standby or Sleep particular modules when needed is also part of this generic platform strategy.

- Supply: the choice of supply depends on the installation and necessary in the case of an autonomous embedded system. it is necessary to think of a strategy linked to a battery, rechargeable from sources available in the environment or from of a fixed charge. Sometimes the systems may simply be fed from the sector here also it depends on sources available in the environment of the sensor.

The determination of the different parts of the system permits us to have a better knowledge about which approach of development is the most indicated. The $\mathrm{V}$ cycle had been applied to the electronic

The first step was based on a bulky system described in the figure 2. We used the techniques of Pitch/ Catch and Pulse / Echo [5] for the inspection of aluminum and composite component

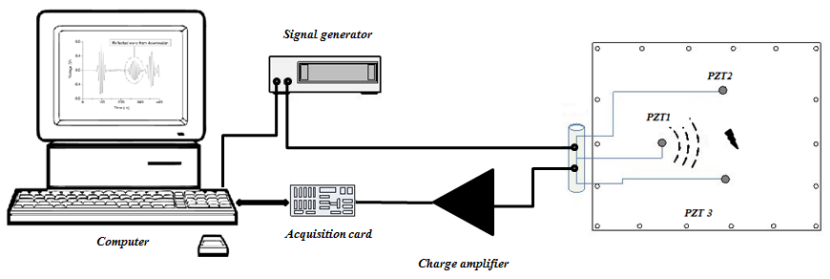

Fig. 2. Our Structural Health Monitoring system description before integration

The experiment bench developed specifically breaks down into several parts: the sensor, the conditioning electronics, data acquisition card and finally the software interface.

The operating principal is simple: the calculation unit transmits the desired waveform to the signal generator (Lamb wave [6]). The generator output is connected to a sensor $(1,2,3)$ put on a single or broadcast program, sensor is connected to conditioning electronics itself connected to a data acquisition card; the signals are acquired, compared and shaped under Matlab®. The reflected signals allow us to establish a diagnosis, depending on the type of reflection, we can confirm or not the presence of a defect. In the literature [7], we can find the right type of wave for our case study, large surface plate with low thickness; it results from the modulation of a sinusoidal signal modulated by a Hanning function [8].

We can exploit the Lamb waves in detecting defects directly, namely the identification from a time signature and 
extraction of the echoes by thresholding on time signals. The approach that we tested in aircraft structural components and composite AL2024 can identify cracks type defects. The exploitation of Lamb waves allows us to identify damage through the reflections due to defects in the time domain. We were also able to locate defects by triangulation and show that the detection error in the two sensors is possible with a minimum error when the crack and the sensors are along the axes of propagation of the generated waves

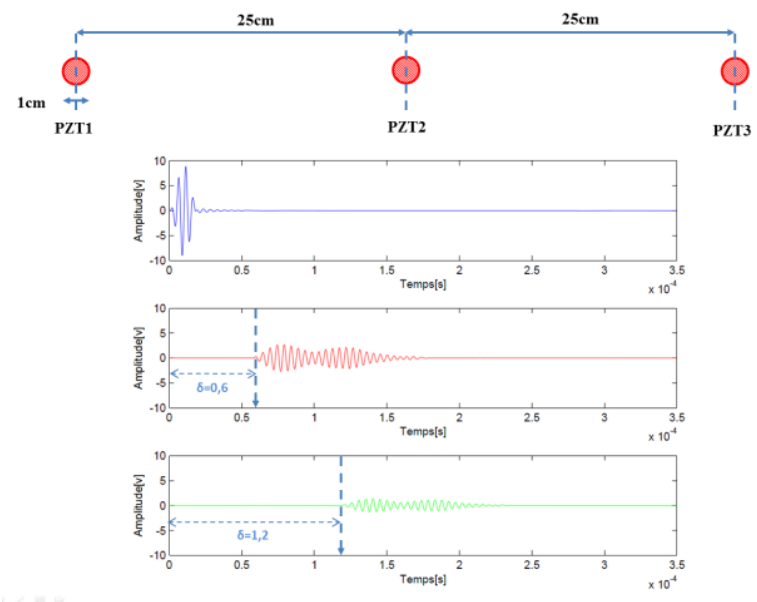

Fig. 3. Mesure of Lamb wave propagation on a sample of healthy Al2024

The figure 3 is representation of our results on a healthy structure we can see that le lamb wave propagate its modes without any echo due to a default unlike what we can see in figure 4 where we can see appear another very attenuated wave which is due to the crack. The case exposed here is the simplest one. We can also detect multiple defects using different algorithm.
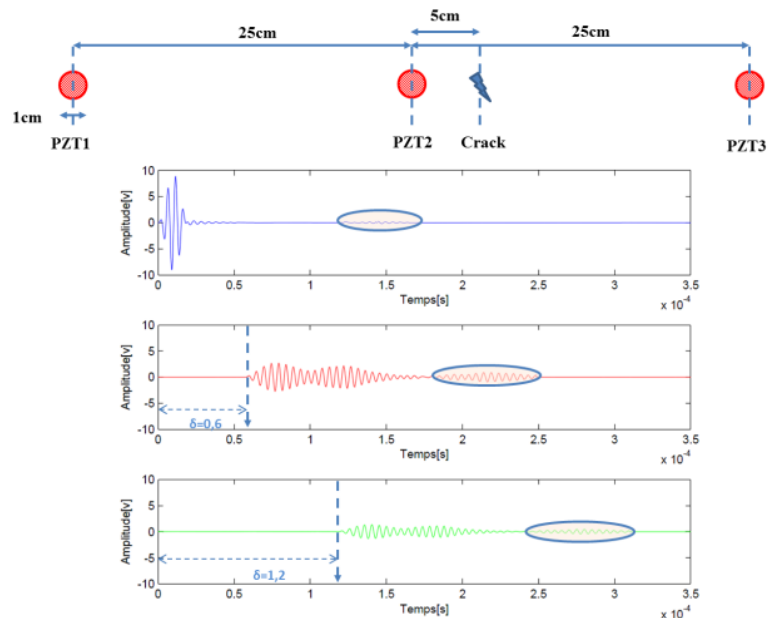

Fig. 4. Mesure of Lamb wave propagation on a sample of damaged Al2024

According to the results obtained, and knowing that detection is possible based on a temporal signature of our sensor. We tried to work on an integration of this principal Based on the V cycle model.
Structural Health Monitoring is a new field of research which can consist in a large and complex system which is able to provide us at any time the state of our structure. According to that we started by a simplification of the global system by working on a simple node, and making it focusing on the detection of reflected waves of defaults.

\section{IMPLEMENTATION OF A V CYCLE}

V- Model means Verification and Validation model, most of time applied to the development of software project, it's also used in hardware conception, it is mostly use in development of small to medium project, considering that the base system is quiet simple, the use of $\mathrm{V}$ cycle was the logical option.

The V-Model uses the so-called Subject of the Project for concretizing the framework of the approach. The V-Model supports the development of software (SW), hardware (HW), complex or embedded hardware and software systems (HW and SW) and the system integration [9].

Considering that the implementation of a system on a programmable board dedicated to prototyping is a cross between hardware and software V cycle is the answer.

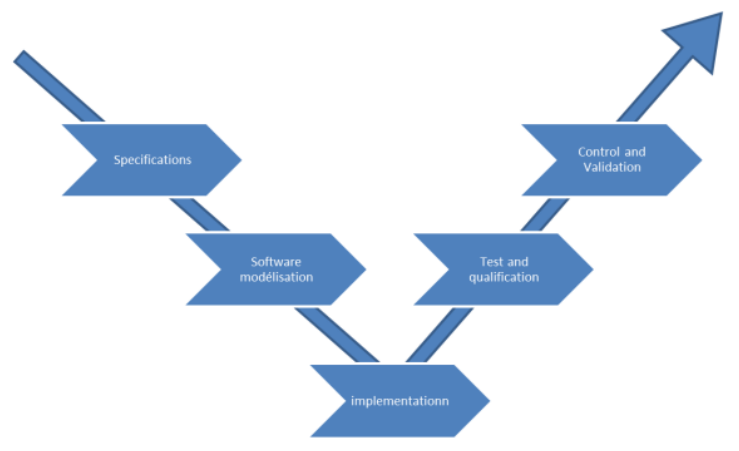

Fig. 5. V Cycle model design flow of conception for hardware design

The figure 5 is a representation of a simplified $\mathrm{V}$ cycle model used during the development; according to this design flow.

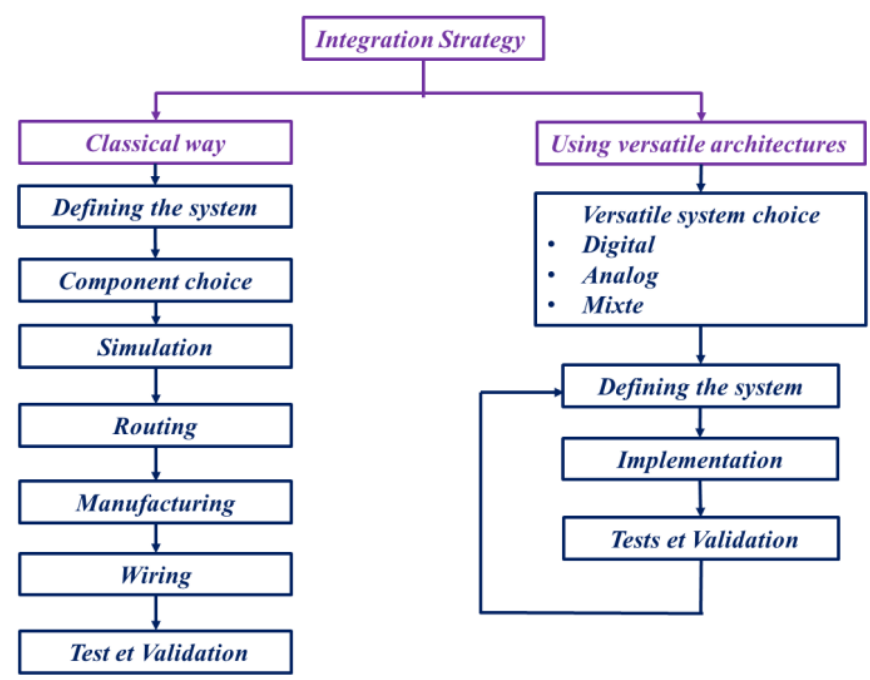

Fig. 6. integration by classical flow and flow-based reconfigurable platform 
The figure 6 is a flow describing two different approaches for hardware conception; we can see the major advantage of using versatile architectures in hardware development. We can re-implement partially or completely as much as it is necessary.

First of all, define the functional description of the system using concurrent process programming languages. After that, perform HW/SW partitioning using unified representation of data/control flow. Then, perform the interface synthesis of a system using hardware and software synthesis approach. The final step for the HW/SW co-design process is the system-level integration [10].

The programmable chip chosen for this work is a SoC (System on Chip) called Zynq ${ }^{1}$, the chip is the core of the system connected to the sensor and to an electronic of conditioning. The implementation of the algorithm of detection, permit us to validate the starting specification.

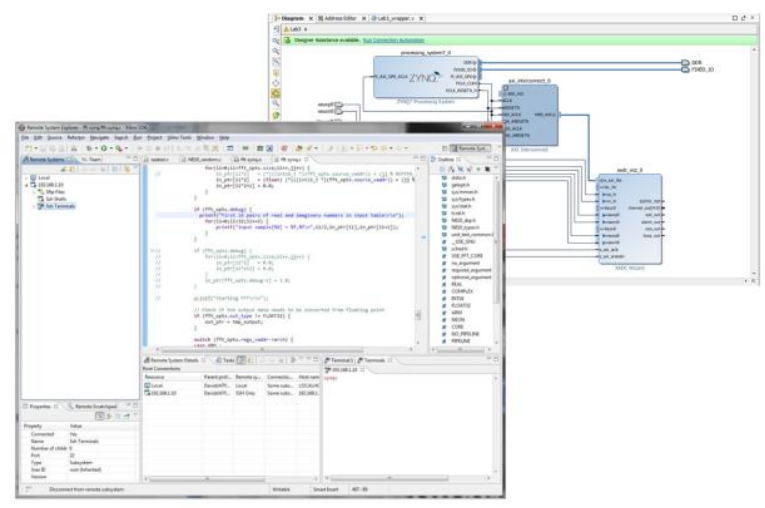

Fig. 7. Catch screan of the developpement part in $\mathrm{SDK}^{2}$ and Vivado ${ }^{3}$

After developing the system detection using the suit Xilinx represented in figure7, we implemented the global system on our chip.

The test and qualification step consisted on the repetition of the measures and adding some noise to simulate an exposition to external conditions. The calculated delta (time of flight in our measures) is our reference, considering that if the time of flight has an error of approximatively $2 \%$ permit us a good localization of default in structure.

\footnotetext{
${ }^{1}$ Based on the Xilinx All programmable SoC architecture, the Zynq®7000 All Programmable SoCs enable extensive system level differentiation, integration, and flexibility through hardware, software, and I/O programmability.

${ }^{2}$ The Software Development Kit (SDK) is the Xilinx Integrated Design Environment for creating embedded applications on any of Xilinx' award winning microprocessors for Zynq ${ }^{\circledR}-7000$ All Programmable SoCs, and the industry-leading MicroBlaze ${ }^{\mathrm{TM}}$. The SDK is the first application IDE to deliver true homogenous and heterogeneous multi-processor design and debug.

${ }^{3}$ The Vivado® Design Suite delivers a SoC-strength, IP-centric and system-centric, next generation development environment that has been built from the ground up to address the productivity bottlenecks in system-level integration and implementation. The Vivado Design suite is a Generation Ahead in overall productivity, ease-of-use, and system level integration capabilities
}
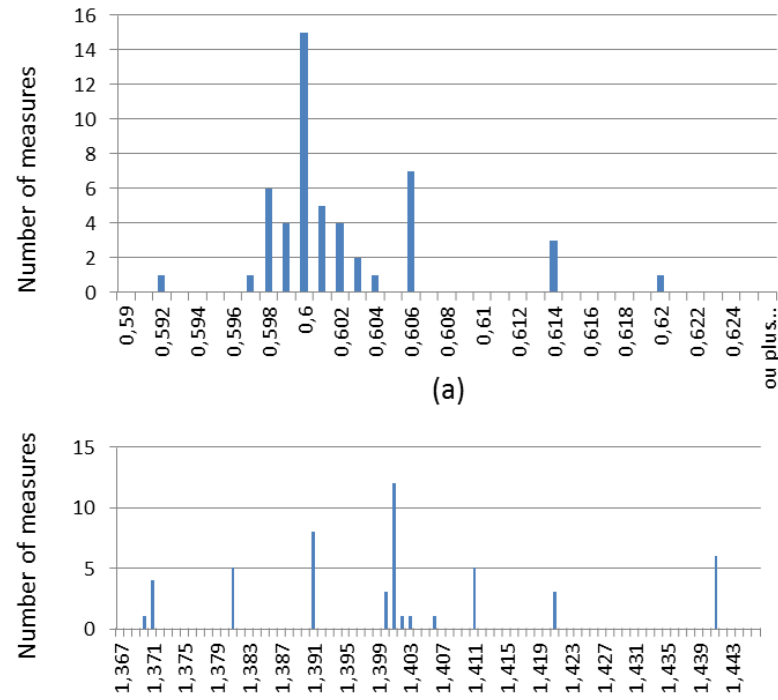

(b)

Time of Flight $\times 10^{-4} \mathrm{~s}$

Fig. 8. Mesures of different Time of flight of Lamb waves according to 100 repeted measures (a) healthy structure (b) unhealthy one.

We can see according to the measures that the system has some differences mainly due to detection threshold, but validate the detection with a quiet good ratio. According to the $\mathrm{V}$ cycle all the steps was respected and permits us to save time and energy development cause this approach gives us a thread in the HW and SW part.

\section{CONCLUSION}

We just exposed the conception of a new system dedicated to Structural Health Monitoring based on a new kind of System on Chip called Zynq, the complexity of the chip and the strategy of detection needed a strong methodology to avoid us wasting time.

The development of new approaches of developing complex system is a powerful tool for the designers and developers, considering the size and the complexity of the project leads us to the best choice. The $\mathrm{V}$ cycle is well known approach some say outdated but it is still working very well even with the evolution of conception and the appearance of co-design.

\section{REFERENCES}

[1] Farrar, C. R., \& Worden, K. (2012). An Introduction to Structural Health. New Trends in Vibration Based Structural Health Monitoring, $520,1$.

[2] Toman, J., Kerlín, T., \& Singule, V. (2011). Application of the V-Cycle Development in the Aerospace Industry. Engineering Mechanics, 18(56), 297-306.

[3] Balageas, D., Fritzen, C. P., \& Güemes, A. (Eds.). (2006). Structural health monitoring (Vol. 493). London: ISTE. 
[4] Zedek, S. (2015). Intégration d'architectures mixtes reconfigurables: Application à la détection de défauts dans des structures hétérogènes (Doctoral dissertation, INSA Toulouse).

[5] Giurgiutiu, V. (2003, August). Lamb wave generation with piezoelectric wafer active sensors for structural health monitoring. In Smart Structures and Materials (pp. 111-122). International Society for Optics and Photonics.

[6] Alleyne, D. N., \& Cawley, P. (1992). Optimization of Lamb wave inspection techniques. $N d t \&$ E International, 25(1), 11-22.

[7] D. N. Alleyne et P. Cawley, «Optimization of lamb wave inspection techniques», NDT E Int., vol. 25, no 1, p. 11-22, 1992.

[8] V. Giurgiutiu, Structural Health Monitoring: with Piezoelectric Wafer Active Sensors. Academic Press, 2007.

[9] IABG. "Das V-Modell". Accessed 21st July 2011. This is in German/ English.
[10] Khan, L.; Jeong, T.T.; Park, G.; Ambler, A.P., "A HW/SW Co-design Methodology: An Accurate Power Efficiency Model and Design Metrics for Embedded System," Software Engineering, Artificial Intelligences Networking and Parallel/Distributed Computing, 2009. SNPD '09. 10th ACIS International Conference on , vol., no., pp.3,7, 27-29 May 2009 doi:10.1109/SNPD.2009.71 